bin

OCT 162830

$0 S T$

\title{
Multiphase Fluid Flow and Heat Transfer at Hanford Single-Shell Tanks - A Progress Report on Modeling Studies
}

\author{
Karsten Pruess \\ Earth Sciences Division, Lawrence Berkeley National Laboratory \\ University of California, Berkeley, CA 94720
}

April 2000

This work was supported by the U.S. Department of Energy under Contract No. DE-AC03-76SF00098 through Memorandum Purchase Order 248861-A-B2 between Pacific Northwest National Laboratory and Lawrence Berkeley National Laboratory. 


\section{DISCLAIMER}

This report was prepared as an account of work sponsored by an agency of the United States Government. Neither the United States Government nor any agency thereof, nor any of their employees, make any warranty, express or implied, or assumes any legal liability or responsibility for the accuracy, completeness, or usefulness of any information, apparatus, product, or process disclosed, or represents that its use would not infringe privately owned rights. Reference herein to any specific commercial product, process, or service by trade name, trademark, manufacturer, or otherwise does not necessarily constitute or imply its endorsement, recommendation, or favoring by the United States Government or any agency thereof. The views and opinions of authors expressed herein do not necessarily state or reflect those of the United States Government or any agency thereof. 


\section{DISCLAIMER}

Portions of this document may be illegible in electronic image products. Images are produced from the best available original document. 


\title{
Multiphase Fluid Flow and Heat Transfer at Hanford Single-Shell Tanks - A Progress Report on Modeling Studies
}

\author{
Karsten Pruess \\ Earth Sciences Division, Lawrence Berkeley National Laboratory \\ University of California, Berkeley, CA 94720 \\ e-mail: K_Pruess@lbl.gov
}

April 2000

\begin{abstract}
Numerical simulation studies have been performed to obtain a better understanding of fluid flow and heat transfer in the unique hydrogeologic system created by the Hanford tanks. The preliminary model presented here emphasizes an understanding of processes rather than a representation of site-specific detail. Our simulation considers moisture migration under nonisothermal, multiphase conditions. It includes phase change (vaporization-condensation) and gas phase flow effects, but no allowance has yet been made for dissolved solids and chemical interactions, as would be required to describe fluids leaked from tanks. Problem parameters are loosely patterned after conditions at tank SX-108. Our simulations indicate that vapor diffusion is an important moisture transport mechanism that promotes formation dry-out beneath the tanks.
\end{abstract}

\section{Introduction}

Of fifteen single-shell tanks at the 241-SX tank farm ten are known leakers (Ward et al., 1997). Numerical modeling studies have been initiated with the objective to obtain a better understanding of fluid flow, solute transport, and heat transfer processes near leaking single-shell storage tanks at Hanford. Our current emphasis is on developing a comprehensive process description, rather than a simulation of a specific tank.

Emplacement of the tanks led to large changes in the hydrogeological conditions at the site. The following effects may be distinguished.

- Sediments down to approximately $16 \mathrm{~m}$ depth were removed during construction and backfilled after tank emplacement, altering the hydrogeologic properties of the material.

- A layer of gravel and coarse sand of approximately $2 \mathrm{~m}$ thickness was placed on top of the tanks. This will allow precipitation to migrate more rapidly to greater depth, greatly increasing net infiltration by reducing the fraction of infiltration that can be removed by evapotranspiration.

This work was supported by the U.S. Department of Energy under Contract No. DE-AC03-76SF00098 through Memorandum Purchase Order 248861-A-B2 between Pacific Northwest National Laboratory and Lawrence Berkeley National Laboratory. 
- The "umbrella" effect of the tanks will cause infiltrating water to pond atop the tanks and be diverted sideways, with much increased water fluxes around the perimeter of the tanks.

- Elevated formation temperatures from radioactive decay heat released in the tanks may cause vaporization-condensation effects with associated redistribution of moisture.

- Tank leaks can introduce hot and highly saline aqueous fluids into the subsurface, whose thermophysical properties and flow behavior may be quite different from pure water. Further changes in flow behavior could result from chemical alteration of the sediments due to reactions with the fluids.

The preliminary model presented here aims at improving our understanding of the effects of the tanks on moisture distribution and migration in the vadose zone. At present, no allowance is made for tank leaks and the physical and chemical effects from such leaks. The aqueous phase is represented as pure water, while formation gas is modeled as a mixture of air and vapor. Coupled fluid flow and heat transfer processes accounted for by our model include seepage of water under gravitational, viscous, and capillary forces, gas phase advection and interdiffusion of air and vapor, heat conduction, and vaporization-condensation effects with associated heat transfer. Vapor pressure lowering (VPL) effects from capillary suction and adsorption of liquid water on solid grains are included. For some cases the migration of a conservative solute was also modeled. Of particular interest are moisture migration beneath the land surface and its interaction with tank heat and the umbrella effect of the tanks. Some of the processes are represented with a higher degree of detail and realism than others. All simulations were performed with LBNL's general purpose code TOUGH2 (Pruess et al., 1999).

\section{Problem Specifications}

We have freely borrowed parameters used in previous studies, but we have only made a preliminary survey of existing work in this area. For many parameters undoubtedly more realistic estimates will be available than were used here. An important purpose of this work is to establish a "reference case," in terms of process models and parameter choices, that can provide a preliminary outlook on system behavior and aid in focusing future modeling work as well as field observations. We envision a process of iterative model refinement, where successively more detailed and specific descriptions and parameters are adopted to eventually arrive at a realistic representation of subsurface conditions at the SX tank farm.

A summary of parameters and constitutive relations needed for thermohydrologic modeling of flow and transport in the vadose zone at Hanford tanks is given in Table 1. Note that only a 
subset of these parameters is used in the present study which is limited to a first exploration of selected simplified scenarios. Additional parameters will be required for modeling chemical interactions between leaked tank fluids and the sediments. In terms of controls on flow and transport behavior, some parameters are more important than others.

Table 1. Parameters for thermohydrologic modeling at Hanford tanks \#

flow and transport

- permeability

- porosity

$\|$ and their spatial variability (within as well as between

- characteristic curves (liquid and gas relative permeability, capillary pressure), and their dependence on phase saturation, as well as on temperature and composition of the aqueous phase

- molecular diffusion: tortuosity coefficients, enhancement factor for vapor diffusion (both dependent on phase saturation)

- hydrodynamic dispersion: dispersivities in a conventional Fickian model; coupling coefficients between different subcontinua in a multi-region approach

fluid properties

- density, viscosity, enthalpy, vapor pressure, surface tension, wetting angle, diffusion coefficients (as function of temperature, pressure, and composition)

land surface boundary conditions

- atmospheric conditions of pressure, temperature, relative humidity, wind speed, precipitation

- net infiltration, heat and moisture transfer coefficients

thermal parameters

- density and specific heat of solid grains

- thermal conductivity of medium (dependent on saturation and temperature, possibly also on temperature gradient)

tank geometry and leak history

- tank radius and height; emplacement configuration

- locations, rates, timing of leaks; composition of leaked fluids

\# many of these parameters are spatially variable, and often they may be time-dependent as well

\subsection{Geometry}

The 241-SX tank farm includes 15 single shell tanks that are placed in a regular pattern in five rows and three columns (Conway et al., 1997; see Fig. 1) with 30.4 m spacing between tank centers (Piepho, 1999). To simplify the analysis we consider the vertical planes that bisect the lines between tank centers as planes of symmetry. This will only be approximately valid even for the centrally located tank SX-108, because of different heat loads from different tanks and intrinsic variability in hydrogeologic properties. However, this simplification is appropriate for a first 
exploration of coupled multiphase fluid and heat flow effects. It greatly facilitates the analysis, because it is only necessary to model the shaded region in Fig. 1, with "no flow" conditions applied at the lateral boundaries. For this initial study we make a further approximation and replace the rectangular model domain by a cylinder with radius chosen in such a way as to preserve the cross-sectional area, i.e., $\pi \mathrm{R}^{2}=30.4 * 30.4 \mathrm{~m}^{2}$, so that $\mathrm{R}=17.15 \mathrm{~m}$. The simulation model then simplifies to a two-dimensional $\mathrm{R}-\mathrm{Z}$ section (radius-depth). A summary of geometric parameters used in the model appears in Table 2.

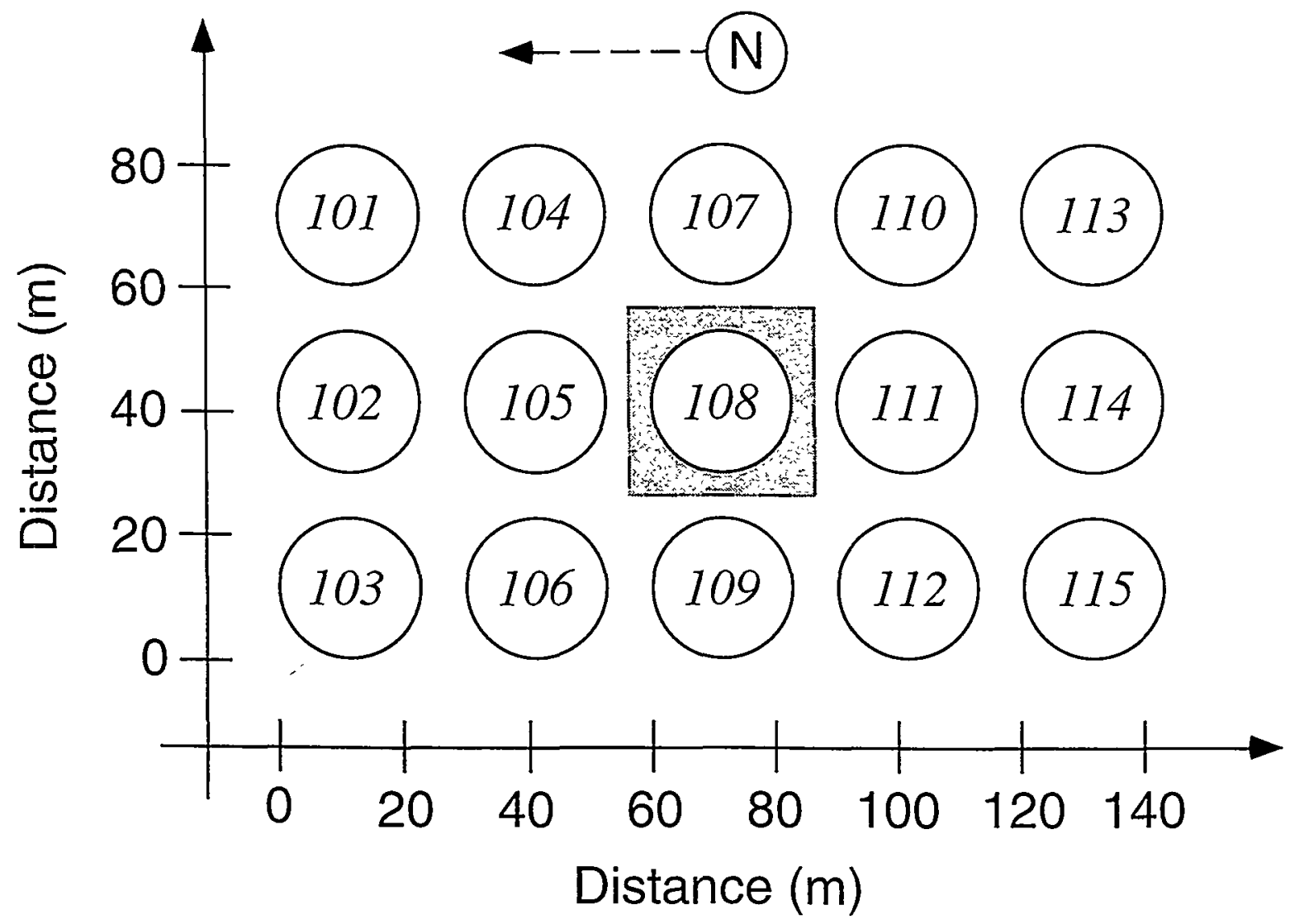

Figure 1. Plan view of the 241-SX tank farm, after Conway et al. (1977).

The shaded region around tank SX-108 indicates an approximate symmetry domain

\subsection{Hydrogeology}

Most of the hydrogeologic parameters used in the present study were taken from Ward et al. (1996), with certain modifications (see below). It is acknowledged that the Ward et al. (1996) report has remained unpublished and was superseded by a later more comprehensive study (Ward et al., 1997). However, the parameterizations used in Ward et al. (1996) are simpler than those used in their later (1997) report, and were considered adequate for this preliminary study. We adopt a simple layer-cake stratigraphy as used by Ward et al. (1996). Slight modifications in layer 
thickness were made; following Gee (2000) we take the depth to which backfill is present as $16 \mathrm{~m}$. The depth to the water table is $64 \mathrm{~m}$, but our model extends to a depth of $68 \mathrm{~m}$. A saturated zone of approximately $4 \mathrm{~m}$ thickness was included in the model to be able to accommodate barometric pressure variations at the land surface without inducing spurious flows at the water table boundary. (No simulations with variable barometric pressure have yet been made.) Table 3 gives the stratigraphy used in our model, and Fig. 2 shows the R-Z section modeled, including the tank. We use two different backfill domains, to be able to represent differences in hydrogeologic properties between deeper backfill and shallower backfill atop the tanks, although no such variation in backfill properties has yet been modeled. Note that our model includes backfill of $0.5 \mathrm{~m}$ thickness beneath the tank.

Table 2. Geometric parameters.

\begin{tabular}{|c|c|c|}
\hline parameter & value & source \\
\hline tank radius & $11.4 \mathrm{~m}$ & (Gee, 2000) \\
\hline tank height & $\begin{array}{l}13.5 \mathrm{~m} \text { (to } \mathrm{R}=7.4 \mathrm{~m} \text { ), then } \\
\text { decreasing to } 11.5 \mathrm{~m} \text { at } \mathrm{R}=11.4 \mathrm{~m}\end{array}$ & $\begin{array}{l}\text { (Gee, 2000) } \\
\text { (Piepho, 1999) }\end{array}$ \\
\hline depth of burial & $\begin{array}{l}2 \mathrm{~m} \text { at top of tank } \\
4 \mathrm{~m} \text { at perimeter }\end{array}$ & $\begin{array}{l}\text { (Gee, 2000) } \\
\text { (Piepho, 1999) }\end{array}$ \\
\hline outer radius of model & $17.15 \mathrm{~m}$ & $\begin{array}{l}\text { preserve cross-sectional area of } \\
\text { symmetry domain (see Fig. 1) }\end{array}$ \\
\hline depth of excavation & $16 \mathrm{~m}$ & (Gee, 2000) \\
\hline
\end{tabular}

Table 3. Stratigraphic sequence at 241-SX tank farm, after Ward et al. (1996).

\begin{tabular}{|l|c|c|}
\hline unit & thickness & to depth \\
\hline \hline backfill & $16 \mathrm{~m} \mathrm{(a)}$ & $16 \mathrm{~m}$ \\
\hline Hanford fine sand & $22 \mathrm{~m} \mathrm{(a)}$ & $38 \mathrm{~m}$ \\
\hline Plio-Pleistocene & $7 \mathrm{~m}$ & $45 \mathrm{~m}$ \\
\hline Upper Ringold & $19 \mathrm{~m}$ & $64 \mathrm{~m} \mathrm{(b)}$ \\
\hline
\end{tabular}

(a) backfill thickness was increased from $15 \mathrm{~m}$ used by Ward et al. (1996) to $16 \mathrm{~m}$, and thickness of the Hanford fine sand unit was reduced from $23 \mathrm{~m}$ to $22 \mathrm{~m}$

(b) depth to water table; our model domain extends to $68 \mathrm{~m}$ depth 


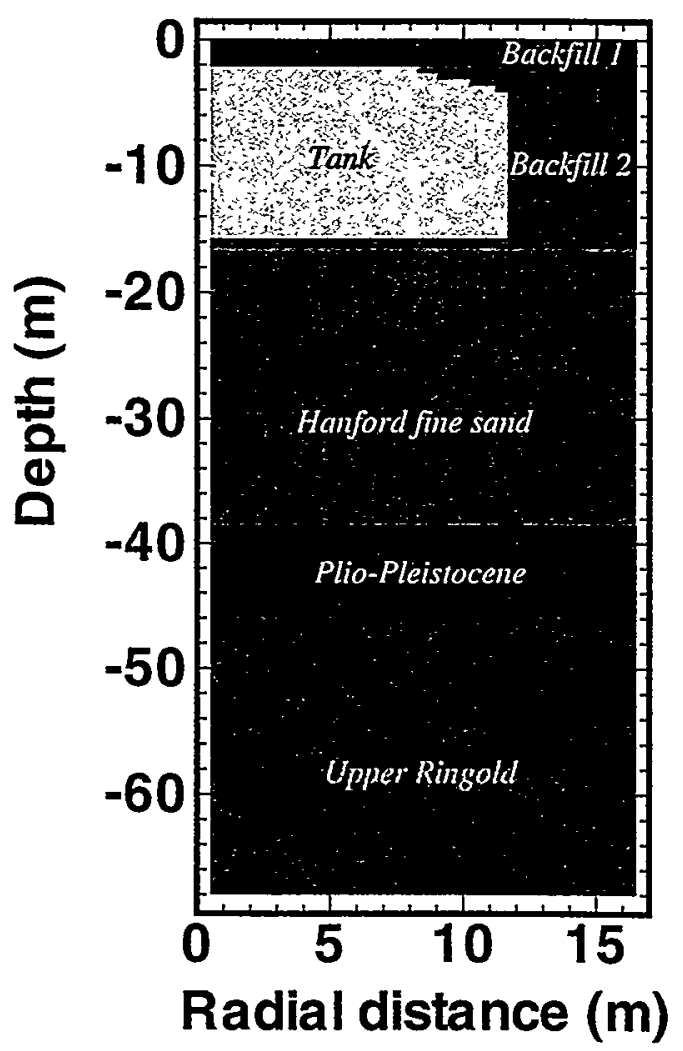

Figure 2. Vertical R-Z section through model domain, showing stratigraphic units (after Ward et al., 1996).

A summary of the hydrogeologic and thermal parameters used in the simulations is given in Table 4. Each stratigraphic unit is modeled as a single homogeneous porous medium. Some comments and observations are in order about the parameter choices made. Following Ward et al. (1996), the anisotropy ratio of horizontal:vertical permeability was taken as $2: 1$; a more common value is 10:1 which was also used by Piepho (1999). The absolute permeabilities as adopted here from Ward et al. (1996) are often considerably different from those used by Piepho (1999) for comparable stratigraphic horizons, in some cases by several orders of magnitude. For example, in the Plio-Pleistocene unit Ward et al. (1996) use a horizontal permeability of $2.72 \mathrm{e}-11 \mathrm{~m}^{2}$, while Piepho's (1999) hydraulic conductivity of $\mathrm{K}=0.41 \mathrm{~m} / \mathrm{yr}$ translates into a permeability of $1.3 \mathrm{e}-15$ $\mathrm{m}^{2}$. Large differences between Ward et al. (1996) and Piepho (1999) also exist in relative permeability and capillary pressure parameters. Obviously, in future work an effort should be made to reconcile these discrepancies. For aqueous phase relative permeability and capillary pressure we use the van Genuchten-Mualem model (Mualem, 1976; van Genuchten, 1980). The parameter $S_{l r}$ in the capillary pressure function was chosen smaller than in the liquid relative permeability function, and was either reduced by two percentage points $\left\{S_{l r}\left(\right.\right.$ for $\left.P_{c a p}\right)=S_{l r}\left(\right.$ for $\left.k_{r l}\right)$ 
Table 4. Hydrogeologic and thermal parameters (a)

\begin{tabular}{|c|c|c|c|c|c|}
\hline $\begin{array}{l}\text { formation } \\
\text { parameter }\end{array}$ & backfill & Hanford & $\begin{array}{l}\text { Plio- } \\
\text { Pleistocene }\end{array}$ & $\begin{array}{l}\text { Upper } \\
\text { Ringold }\end{array}$ & comments \\
\hline $\begin{array}{ll}\text { permeability } & \text { hor. } \\
\left(\mathrm{m}^{2}\right) & \text { vert. }\end{array}$ & $\begin{array}{l}2.48 \mathrm{e}-12 \\
1.24 \mathrm{e}-12\end{array}$ & $\begin{array}{l}1.54 \mathrm{e}-12 \\
7.70 \mathrm{e}-13\end{array}$ & $\begin{array}{l}27.2 \mathrm{e}-12 \\
13.6 \mathrm{e}-12\end{array}$ & $\begin{array}{l}7.4 e-12 \\
3.7 e-12\end{array}$ & $\begin{array}{l}\text { (b) } \\
\text { (c) }\end{array}$ \\
\hline porosity & 0.2585 & 0.4272 & 0.4639 & 0.3785 & (b) \\
\hline $\begin{array}{l}\text { liquid rel. perm. } \\
\mathrm{S}_{\mathrm{lr}}\end{array}$ & $\begin{array}{l}0.6585 \\
0.0774\end{array}$ & $\begin{array}{c}0.321 \\
0.11\end{array}$ & $\begin{array}{l}0.302 \\
0.036\end{array}$ & $\begin{array}{c}0.459 \\
0.1086\end{array}$ & (b), (d) \\
\hline gas rel. perm. $\quad S_{\mathrm{gr}}$ & 0.05 & 0.05 & 0.05 & 0.05 & (e) \\
\hline $\begin{array}{l}\text { cap. pressure } \alpha / \rho g \\
(1 / \mathrm{Pa})\end{array}$ & $10.08 \mathrm{e}-4$ & $10.71 e-4$ & $9.28 \mathrm{e}-4$ & $23.29 e-4$ & (b), (f) \\
\hline tortuosity & 0.25 & 0.25 & 0.25 & 0.25 & (h) \\
\hline grain density $\left(\mathrm{kg} / \mathrm{m}^{3}\right)$ & 2600 & 2600 & 2600 & 2600 & (h) \\
\hline $\begin{array}{l}\text { grain specific heat } \\
\left(\mathrm{J} / \mathrm{kg}{ }^{\circ} \mathrm{C}\right)\end{array}$ & 800 & 800 & 800 & 800 & (i) \\
\hline $\begin{array}{ll}\text { thermal cond. } & \text { wet } \\
\left(\mathrm{W} / \mathrm{m}^{\circ} \mathrm{C}\right) & \text { dry }\end{array}$ & $\begin{array}{l}0.95 \\
0.92\end{array}$ & $\begin{array}{l}1.10 \\
1.03\end{array}$ & $\begin{array}{l}1.70 \\
1.63\end{array}$ & $\begin{array}{l}1.69 \\
1.63\end{array}$ & (i) \\
\hline
\end{tabular}
(a) for boundary and initial conditions see section 2.5
(b) from Ward et al. (1996)
(c) anisotropy ratio 2:1 (Ward, 1996)
(d) $m=1-1 / n$ (notation of van Genuchten, 1980)
(e) Corey's function (1954) is used
(f) assuming $\rho g \approx 1 . e 4 \mathrm{~N} / \mathrm{m}^{3}$
(g) assumed
(h) generic value for sand
(i) from Piepho (1999)

- 0.02$\}$, or was set to zero. This was done to avoid an unphysical feature of van Genuchten's parametrization in which $\mathrm{P}_{\text {cap }}->-\infty$ when $\mathrm{k}_{\mathrm{rl}}-->0$, which will have little impact on unsaturated flow at ambient conditions, but can cause spurious effects in thermally driven systems that may approach dryout (Pruess, 1997). No dependence of capillary pressure on temperature has been allowed at present. For gas phase flow we use the relative permeability function of Corey (1954), given by

$$
k_{\mathrm{rg}}=(1-\overline{\mathrm{S}})^{2}\left(1-\overline{\mathrm{S}}^{2}\right)
$$

where the reduced saturation is 


$$
\bar{S}=\left(S_{l}-S_{l r}\right) /\left(1-S_{l r}-S_{g r}\right)
$$

Generic values are used for density and specific heat of the sand grains. The thermal conductivity values as adopted from Piepho (1999) have unusually small differences between wet and dry conductivities (see Table 4) and may not be realistic. Dependence of thermal conductivity on water saturation is calculated from a formulation due to Somerton et al. (1973),

$$
\lambda\left(S_{1}\right)=\lambda_{\text {dry }}+\sqrt{S_{1}}\left(\lambda_{\text {wet }}-\lambda_{\text {dry }}\right)
$$

\subsection{Fluid Properties}

The aqueous phase is modeled as pure water, with thermophysical properties (density, viscosity, enthalpy, vapor pressure) given by standard steam table equations (IFC, 1967), which represent properties of water and vapor within experimental accuracy. Air is approximated as an ideal gas, and additivity of partial pressures is assumed for air and vapor. The viscosity of airvapor mixtures is computed from a formulation given by Hirschfelder et al. (1954), but using steam table values for vapor viscosity instead of approximations from kinetic gas theory. Henry's law is assumed for solubility of air in liquid water,

$$
\mathrm{P}_{\mathrm{air}}=\mathrm{K}_{\mathrm{h}} \mathrm{x}_{\mathrm{aq}}^{\mathrm{air}}
$$

where $\mathrm{x}_{\mathrm{aq}}^{\mathrm{air}}$ is the mol fraction of dissolved air in the aqueous phase. The Henry's law coefficient $\mathrm{K}_{\mathrm{h}}$ is a function of temperature, varying from $0.43 * 10^{10} \mathrm{~Pa}$ to $1.1 * 10^{10} \mathrm{~Pa}$ over the temperature range from $0-100^{\circ} \mathrm{C}$ (Loomis, 1928). Because air solubility itself is small, this modest variation was here approximated as a temperature-independent $\mathrm{K}_{\mathrm{h}}=10^{10} \mathrm{~Pa}$. Dissolution and exsolution of air, although included in our model, do not appear to be significant effects for the tank problem. Molecular diffusion of air and water vapor in the gas phase is modeled as Fickian, with diffusive flux of component $\mathrm{K}$ (= air, vapor) given by (Pruess et al., 1999)

$$
\mathbf{f}_{\mathrm{g}}^{\mathrm{K}}=-\phi \tau_{0} \tau_{\mathrm{g}} \rho_{\mathrm{g}} \mathrm{d}_{\mathrm{g}}^{\mathrm{K}} \nabla \mathrm{X}_{\mathrm{g}}^{\mathrm{K}}
$$

Here, $\phi$ is porosity, $\tau_{0} \tau_{\mathrm{g}}$ is the tortuosity which includes a porous medium dependent factor $\tau_{0}$ and a coefficient that depends on gas phase saturation $S_{g}, \tau_{g}=\tau_{g}\left(S_{g}\right), \rho_{g}$ is density, $d_{g}^{K}$ is the diffusion coefficient of component $K$ in bulk gas phase, and $X_{\mathrm{g}}^{K}$ is the mass fraction of component $\kappa$. The gas phase tortuosity coefficient is taken equal to gas relative permeability, $\tau_{\mathrm{g}}=\mathrm{k}_{\mathrm{rg}}$. The vapor-air diffusion coefficient is a function of pressure and temperature, and is given by (Vargaftik, 1975) 


$$
d_{\beta}^{K}(P, T)=d_{\beta}^{K}\left(P_{0}, T_{0}\right) \frac{P_{0}}{P}\left[\frac{T+273.15}{273.15}\right]^{\theta}
$$

At standard conditions of $\mathrm{P}_{0}=1 \mathrm{~atm} \equiv 1.01325 \mathrm{bar}, \mathrm{T}_{0}=0{ }^{\circ} \mathrm{C}$, the diffusion coefficient for vaporair mixtures has a value of $2.16 \times 10^{-5} \mathrm{~m}^{2} / \mathrm{s}$; parameter $\theta$ for the temperature dependence is 1.80 (Vargaftik, 1975).

Experimental and modeling studies have established that in unsaturated porous media, vapor diffusion is enhanced relative to the diffusion of non-condensible gases by pore-level phase change effects (Philip and de Vries, 1957; Cass et al., 1984; Webb and Ho, 1998). Enhancement coefficients are poorly known for field-scale systems, and no such effects have been included in the present study.

\subsection{Computational Grid}

The computational grid should be designed as required to meet the objectives of the simulation study. In order to minimize discretization errors it is desirable to use fine gridding, especially in regions where large gradients in thermodynamic state variables are expected. On the other hand, finer discretization increases the computational work, not only by increasing the number of grid blocks, but also because achievable time steps will be smaller. The grid used here represents a compromise between these conflicting demands. We have limited the number and spatial resolution of grid blocks, but we have provided for finer gridding in regions where important process controls are expected. The computational grid as shown in Fig. 3 has 21 blocks in R-direction and 38 layers. The entire tank volume is included in the discretization domain and is shown with dark shading in Fig. 3. The region occupied by the tank is assigned zero permeability in the simulations. Radial grid increments are $\Delta R=1 \mathrm{~m}$ near the tank center, decrease to $0.42 \mathrm{~m}$ near the perimeter of the tank, and then increase to $1.28 \mathrm{~m}$ at the outer boundary of the model domain. Vertical thickness of grid layers varies from $0.5-4 \mathrm{~m}$. Finer gridding is used at the top of the domain, near the bottom of the tank, and at lithologic contacts.

\subsection{Boundary and Initial Conditions}

Actual land surface boundary conditions atop the tanks are complex and highly variable. Net infiltration is determined by an interplay of episodic precipitation and snow melt events with evapotranspiration processes that depend on atmospheric conditions of temperature, relative humidity, and wind speed, as well as on solar irradiation and heat supplied from the tanks. No attempt has been made to model and resolve these complex mass and heat transport processes on the space and time scales on which they are actually occurring. In the present preliminary modeling 


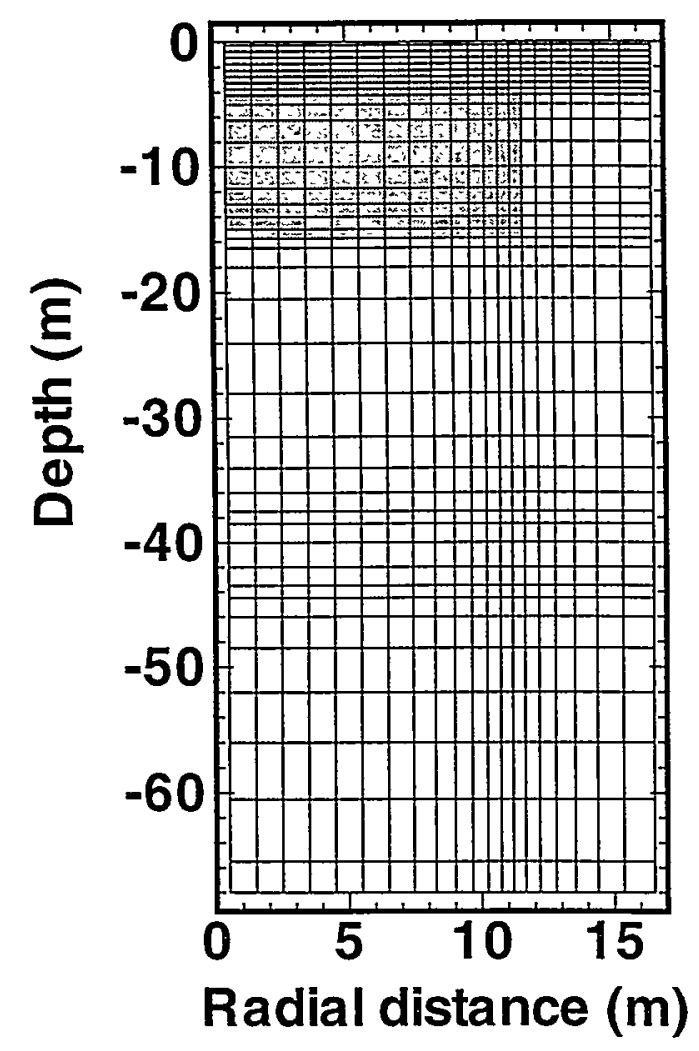

Figure 3. Computational grid for tank study. The tank is shown by dark shading.

study, we follow the standard practice of adopting time-independent boundary conditions at the land surface which are intended to capture long-term averages.

Long-term annual average precipitation at the 241-SX tank farm site is in the range of 160 $190 \mathrm{~mm} / \mathrm{yr}$, but values as high as $300 \mathrm{~mm} / \mathrm{yr}$ have been observed in some years (Ward et al., 1997). Depending on soil conditions and vegetative cover, much of this precipitation may be lost to evapotranspiration. Net infiltration has been estimated to "vary from less than $0.1 \mathrm{~mm} / \mathrm{yr}$ on a variety of soil and vegetative combinations to greater than $130 \mathrm{~mm} / \mathrm{yr}$ on bare basalt outcrops or bare, gravel-surfaced waste sites" (Gee et al., 1992; cited after Ward et al., 1997).

At the land surface boundary, we maintain time-independent conditions of pressure $\mathrm{P}=$ $1.013 \mathrm{e} 5 \mathrm{~Pa}$, temperature $\mathrm{T}=12.8{ }^{\circ} \mathrm{C}$ (Piepho, 1999), and relative humidity $\mathrm{RH}=50 \%$ (preliminary choice). At the bottom of the domain, at a depth of $68 \mathrm{~m}$, time-independent conditions are specified as $\mathrm{P}=1.405 \mathrm{e} 5 \mathrm{~Pa}, \mathrm{~T}=17.26^{\circ} \mathrm{C}$, and air mass fraction $\mathrm{X}_{\text {air }}=0$. The pressure at the bottom boundary was chosen so that the water table would be located at approximately $64 \mathrm{~m}$ depth. 
Bottom temperature was extrapolated from data given by Piepho (1999), who specified $\mathrm{T}=17^{\circ} \mathrm{C}$ at $64 \mathrm{~m}$ depth, corresponding to an average vertical temperature gradient of $0.0656^{\circ} \mathrm{C} / \mathrm{m}$.

Following Piepho (1999), we generate initial (pre-tank emplacement) conditions by running a system with the boundary conditions just mentioned to steady state for an applied net infiltration rate of $10 \mathrm{~mm} / \mathrm{yr}$, which at a water density of $999.51 \mathrm{~kg} / \mathrm{m}^{3}$ corresponds to a mass flux of $3.16726 \mathrm{e}-7 \mathrm{~kg} / \mathrm{m}^{2} \mathrm{~s}$. For the simulation that generates the initial conditions, properties of the tank domain were assumed identical to those of backfill.

\section{Results}

Simulations including tanks were conducted in the flow system set up and prepared as discussed in the previous section. Here we present results for three variations of the simulation problem specified above. In each case, net infiltration following tank emplacement is specified as $50 \mathrm{~mm} / \mathrm{yr}$. The three cases are:

(1) an isothermal case in which the tank is present as an impermeable domain, but no heat generation is considered;

(2) a non-isothermal case in which the tank domain is assigned a constant temperature of 90 ${ }^{\circ} \mathrm{C}$; no vapor-air diffusion is modeled; and

(3) as case (2), but including vapor-air diffusion.

Results for the isothermal case after $t=50 \mathrm{yr}$ of simulation time are given in Figs. 4 and 5 . The plot of water saturations clearly shows the umbrella effect of the tank. Water saturations atop the tank are only slightly elevated (by $3.6 \%$ ) relative to the case with $10 \mathrm{~mm} / \mathrm{yr}$ infiltration and no tank. This is explained by the rather large permeability of the backfill, for which a modest increase in saturation is sufficient to provide the additional relative permeability needed at the higher flux rates. Infiltration applied at the land surface is diverted around the perimeter of the tank, giving rise to a broad finger with excess saturation there. Water flux in this region exceeds average infiltration flux applied at the land surface by an order of magnitude (factor 10.7); water velocity is increased by a factor 6.9 , less than water flux because saturation has also increased. The infiltration shadow of reduced liquid saturation is clearly visible beneath the tank, especially near the center.

A solute tracer was added to the infiltrating water from $t=0$, to be able to distinguish the water infiltrating in the presence of the tank from the moisture that was present initially. Fig. 5 depicts the distribution of tracer after $50 \mathrm{yr}$, showing a broad plume beneath the perimeter of the tank in which downward water migration was accelerated. Tracer concentrations are very small at the lower boundary of the model domain; approximately $0.077 \%$ of the traced water has left the 


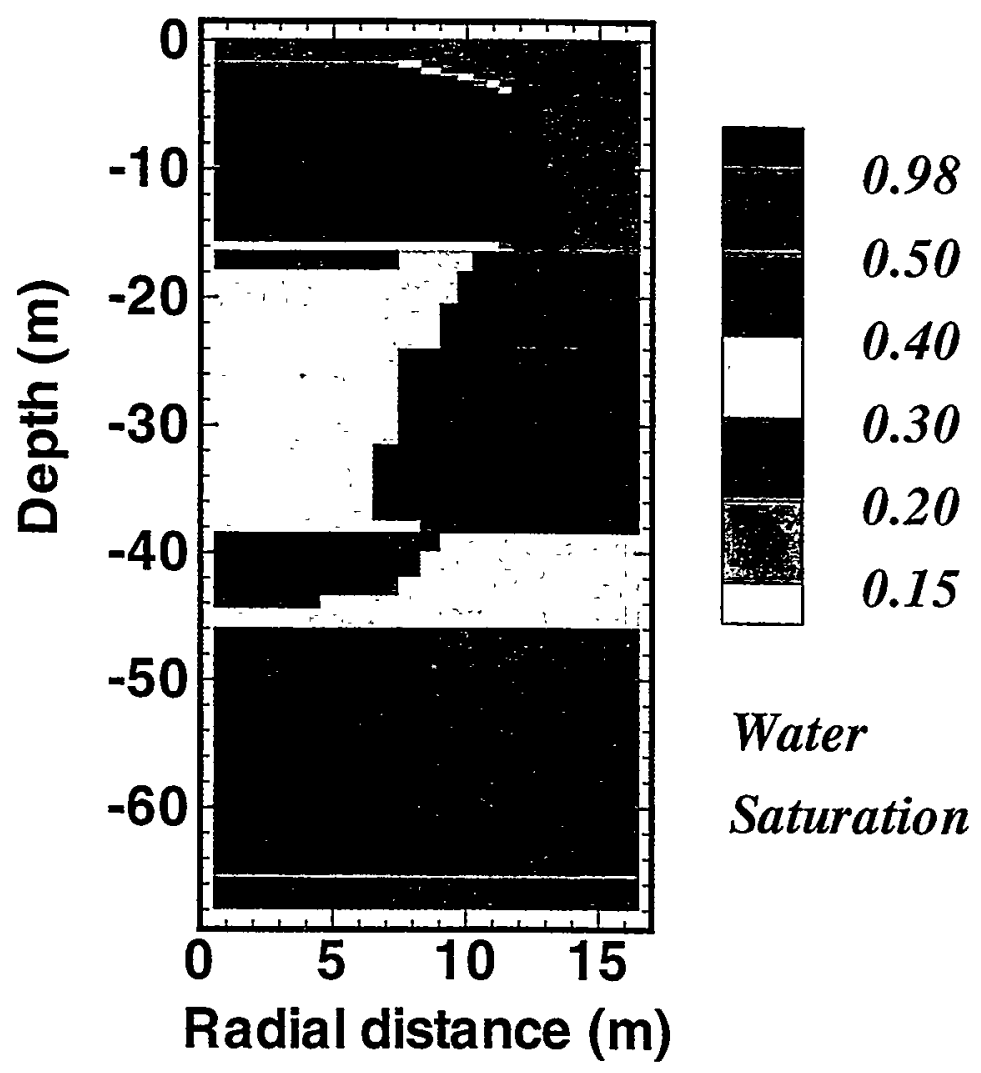

Figure 4. Water saturations after 50 yr for Case (1), no heat effects from tank.

system through the bottom boundary at $\mathrm{t}=50 \mathrm{yr}$. The simulation results should be interpreted with caution, however, because the single-continuum description adopted here is likely to underestimate tracer migration velocities (see below). The net increase in water inventory in the vadose zone is $46.3 \%$ of the cumulative amount injected over 50 years.

The temperature distribution for the nonisothermal Case (2) after $\mathrm{t}=50 \mathrm{yr}$ is given in Fig. 6. Elevated temperatures are seen throughout the entire unsaturated zone. The cooling effect from the land surface boundary is apparent, as is the cooling effect of the infiltrating water. (Recall that the outer boundary of the model domain at $R=17.15 \mathrm{~m}$ is "no flow.") Formation temperatures near the bottom of the tank are slightly above $80^{\circ} \mathrm{C}$, considerably larger than measurements at the site which yielded maximum values near $60^{\circ} \mathrm{C}$ (Conaway et al., 1997). Possible reasons for too high temperatures in the simulation include (a) modeling the tank as a constant $\mathrm{T}=90^{\circ} \mathrm{C}$ boundary may overestimate heat effects (recall that our choice of an approximate symmetry region for modeling implies that all tanks are represented as identical heat sources), (b) the values for thermal 


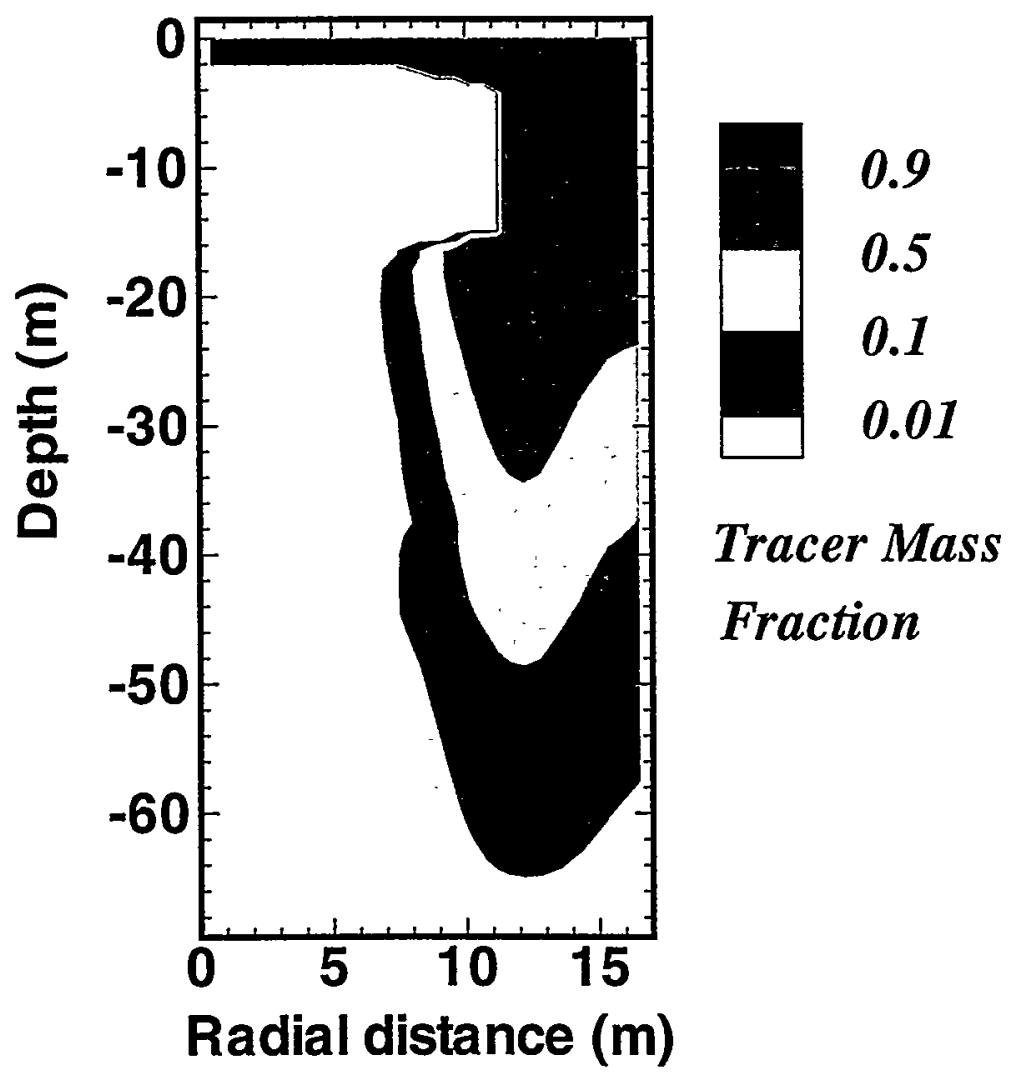

Figure 5. Tracer concentrations after $50 \mathrm{yr}$ for Case (1), no heat effects from tank. Tracer concentration is normalized to mass fraction 1 at the inlet (infiltration boundary at the land surface).

conductivities used here may be too low, reducing heat loss through the surface, and (c) net infiltration may be larger than $50 \mathrm{~mm} / \mathrm{yr}$, providing additional cooling effects.

The plot of tracer concentrations shows that infiltrating water has advanced downward a bit more strongly than in the case without tank heat (compare Figs. 7 and 5). After $50 \mathrm{yr}$, approximately $0.42 \%$ of the traced water has left the system through the bottom boundary. The net increase in water inventory in the vadose zone during the 50-year period is $18.7 \%$, considerably less than for the isothermal case. The main reason for the smaller moisture content are vaporization-condensation effects from the tank heat, which reduce water saturations in the heated regions, compare Fig. 8 with Fig. 4. (We have plotted actual water saturations in grid blocks without any interpolation, to more clearly show changes from gas diffusion effects; see Fig. 9, below.) Vaporization transfers water as vapor into cooler regions where it condenses and drains toward the bottom of the system. Vapor losses through the land surface boundary are very small $(<$ $0.1 \%$ of infiltration). The region of low water saturation beneath the center of the tank is larger 


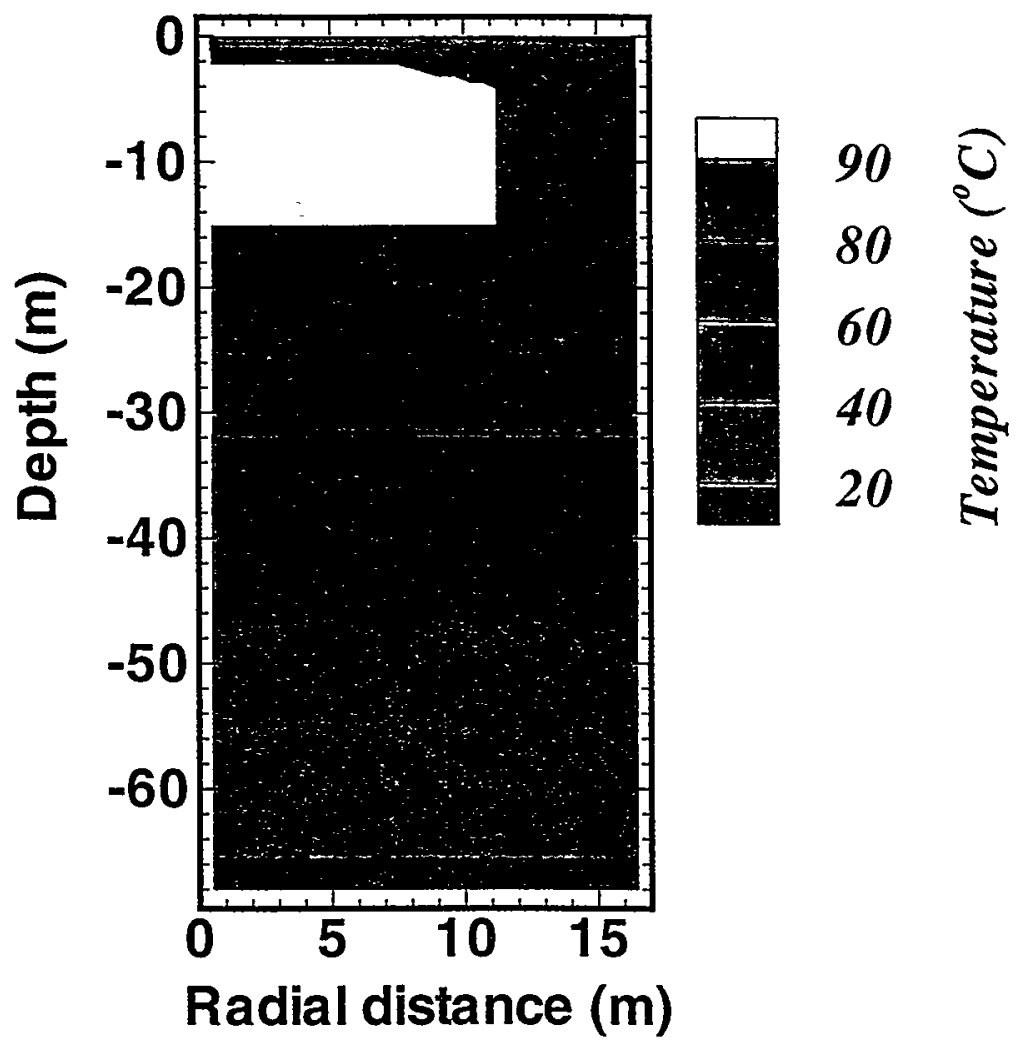

Figure 6. Temperature distribution after $50 \mathrm{yr}$ for Case (2), including heat effects from tank but no vapor diffusion.

than in the isothermal case, as expected. It is interesting to note that the lowest water saturations occur laterally offset from the tank, not in the hottest regions adjacent to it. Water saturations near the tank perimeter are enhanced by seepage diversion into that region.

The temperature distribution is changed little when vapor-air diffusion is included (Case 3; data not shown here), indicating that temperatures are dominated by heat conduction. However, vapor diffusion has significant effects on moisture distribution. The region of low water saturation beneath the tank expands considerably from vapor diffusion and now extends beyond the backfill into the underlying Hanford formation, compare Fig. 9 with Fig. 8. The mechanisms of fluid flow and heat transfer can be appreciated from the plots of capillary pressure, Figs. 10 and 11 . Beneath the central region of the tank diffusive vapor flux is driven primarily downward, opposite the temperature gradient. This gives rise to reduced water saturations and increasingly negative capillary pressures which reach values in excess of $-10 \mathrm{MPa}(-100 \mathrm{bar})$. The capillary gradient draws liquid water up into the hot region where it vaporizes. The vapor flows downward both by advection and diffusion. If only advection is active, the system settles into a very modest suction 


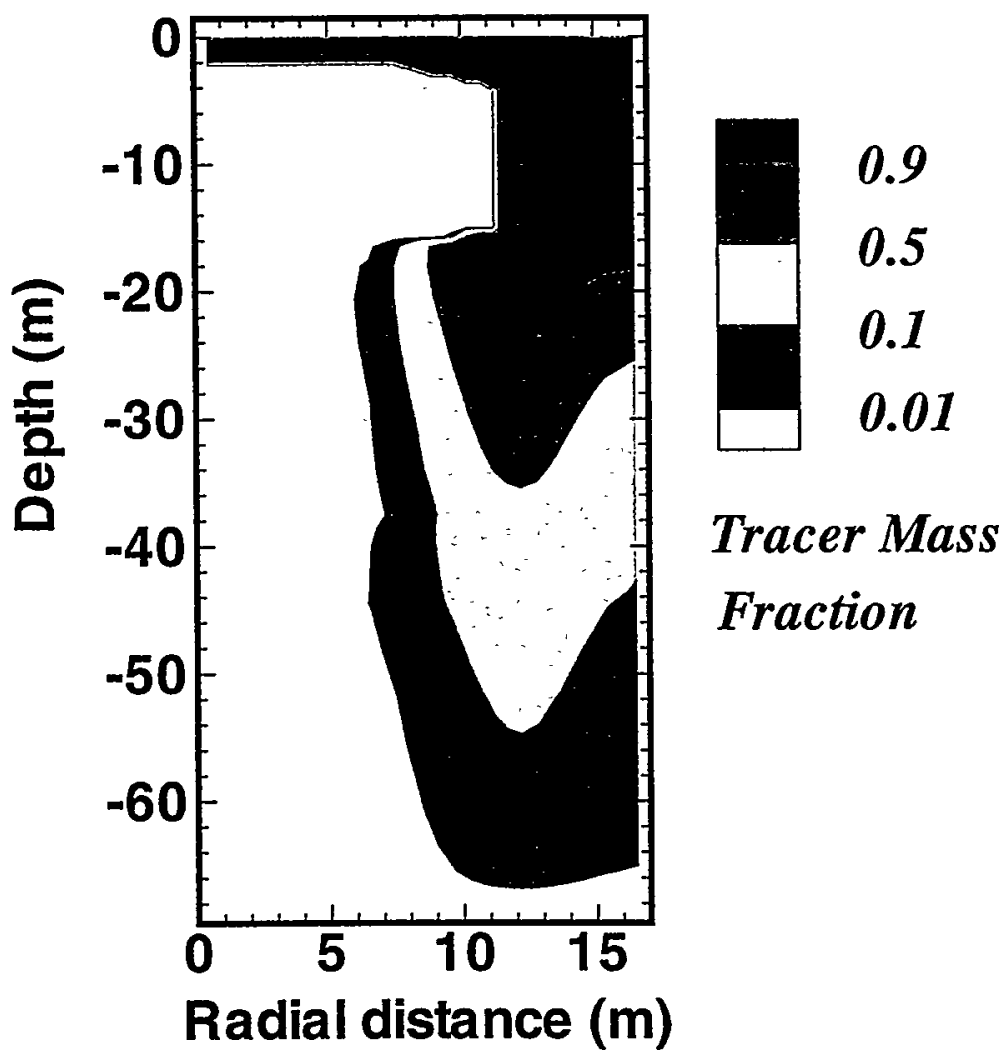

Figure 7. Tracer concentrations after $50 \mathrm{yr}$ for Case (2), including heat effects from tank but no vapor diffusion. Tracer concentration is normalized to mass fraction 1 at the inlet (infiltration boundary at the land surface).

pressure of order $-10 \mathrm{kPa}$ (Fig. 10), while addition of diffusive flux drives the system towards low water saturations with very strong suction pressures.

Our simulation includes vapor pressure lowering (VPL) effects which have an essential role in how vapor diffusion is played out. When VPL is ignored, vapor pressure is equal to saturated vapor pressures as long as two-phase conditions are maintained. This means that the driving force for vapor diffusion, namely, gradients in vapor density, is solely determined by temperature. For a given temperature gradient, diffusive vapor fluxes cannot change until complete dryout is achieved, which will "free" vapor pressure from being constrained to saturated values. We confirmed this by performing a simulation that includes vapor diffusion but no VPL effects, and found that the system is indeed driven to complete dryout beneath the tank. When VPL effects are taken into account, vapor pressure and density can decrease from their saturated values even when liquid water is still present. For example, from Kelvin's equation (Edlefsen and Anderson, 1943) we can estimate that at $-10 \mathrm{MPa}$ suction, vapor pressure is reduced by approximately $6.4 \%$ from its 


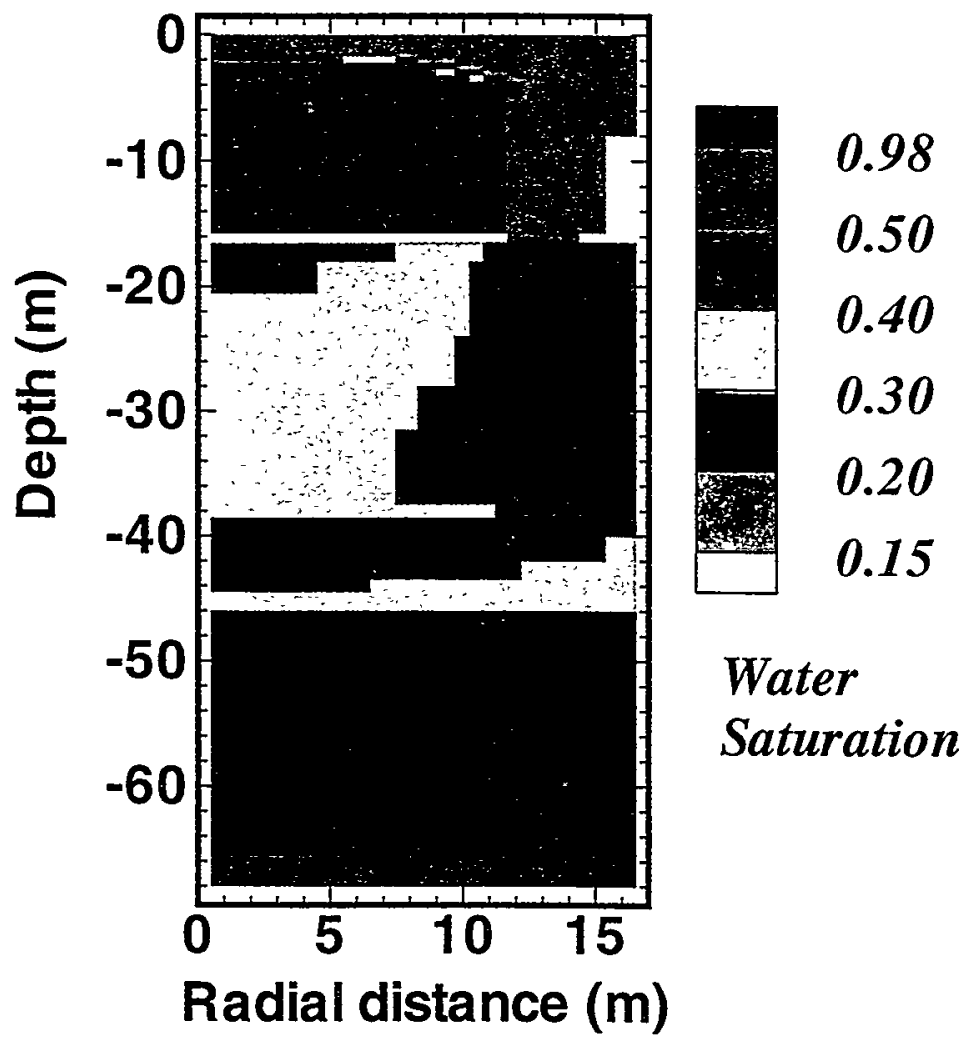

Figure 8. Water saturations after $50 \mathrm{yr}$ for Case (2), including heat effects from tank but no vapor diffusion.

saturated value; at - $100 \mathrm{MPa}$ suction, the reduction is $45.9 \%$. This will decrease the driving force for diffusion, and will allow the system to stabilize at a certain distribution of suction pressures that, depending on capillary pressure functions used, may still correspond to a finite water saturation. The important point here is that the system will be driven to a certain distribution of suction pressures, with water saturations adjusting to whatever values are required by the capillary pressure functions used to achieve these suction pressures.

For van Genuchten's capillary pressure function, the crucial parameter is $\mathrm{S}_{\mathrm{Ir}}$, because suction pressures strong enough to generate significant VPL effects occur only for $S_{1}$ close to $S_{1}$, where $P_{\text {cap }}->-\infty$. In the region beneath the center of the tank, water saturations are very near $S_{l r}$, causing very strong suction pressures, and an extremely strong dependence of $\mathrm{P}_{\text {cap }}$ on small changes in water saturation. In the Case (3) simulation with diffusion and VPL effects, we use $S_{\text {lr }}$ $=0.0574$, and find that water saturations in the seven innermost grid blocks beneath the center of the tank are all within a narrow range of $S_{l r} \leq S_{1} \leq S_{l r}+1 . e-5$, yet suction pressures in these 


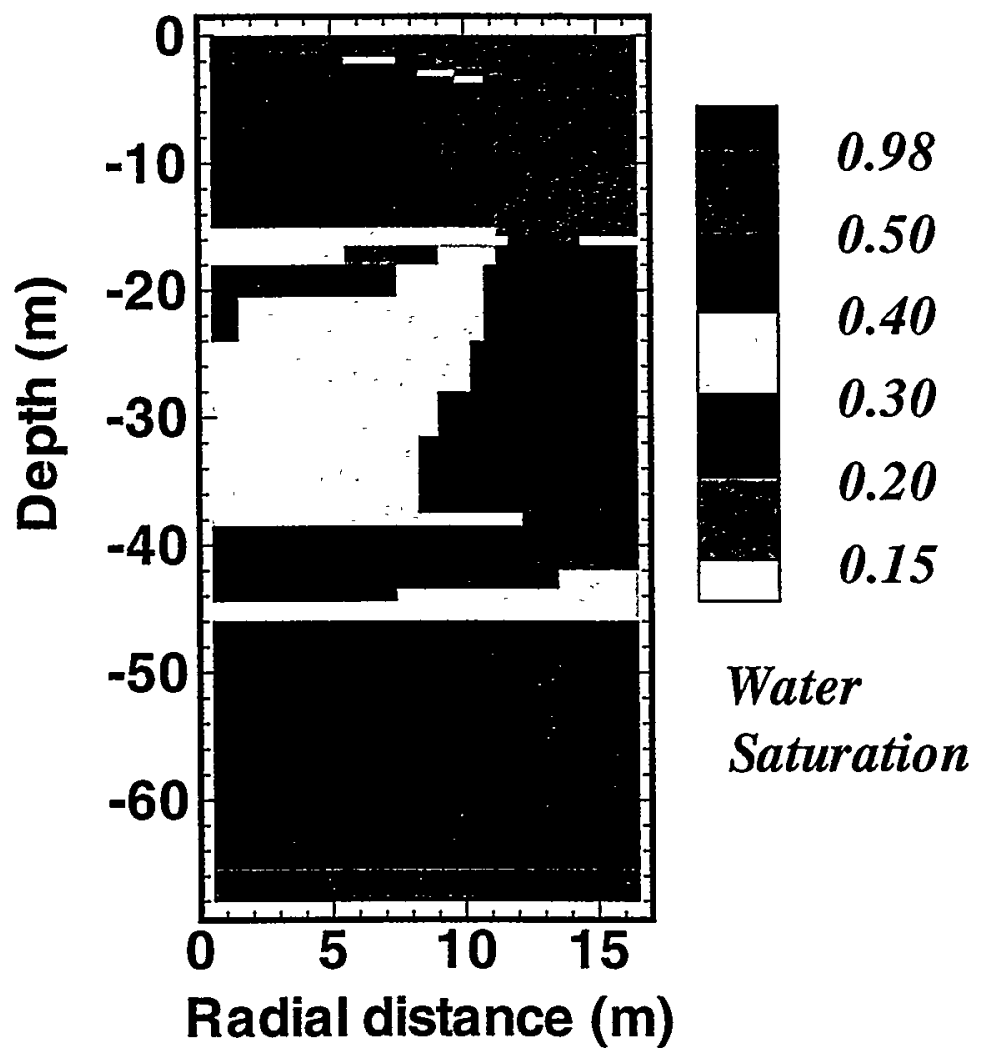

Figure 9. Water saturations after $50 \mathrm{yr}$ for Case (3), including heat effects from tank as well as vapor diffusion.

blocks range from -12.53 $\mathrm{MPa}$ to -3.21 $\mathrm{MPa}$. The extreme sensitivity and non-linearity of capillary pressure in this region makes the simulation very difficult, limiting convergence rates and achievable time steps.

Vapor diffusion also causes some of the infiltration applied at the land surface to be returned to the atmosphere. In our simulation, diffusive vapor flow across the land surface boundary amounts to approximately $5 \%$ of applied infiltration at $\mathrm{t}=50 \mathrm{yr}$. This value may be unrealistically low due to our treatment of land surface boundary conditions. In reality, temperature and relative humidity conditions at the land surface boundary will not be fixed at prescribed atmospheric conditions, but will dynamically evolve in response to fluid flow and heat transfer processes above and below that boundary. Temperatures at the land surface may increase beyond ambient values, which would increase vapor density and thereby enhance moisture removal by diffusion through the atmospheric boundary layer. 


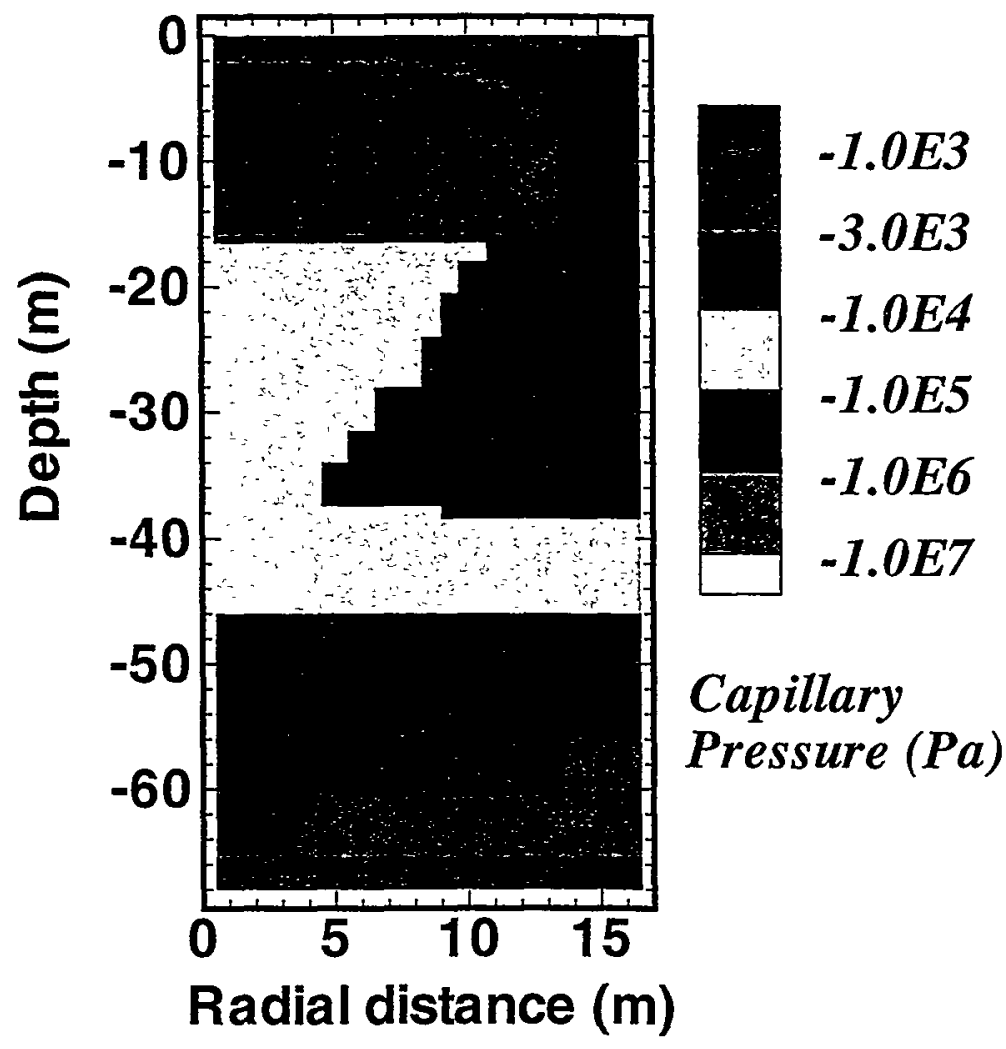

Figure 10. Suction pressures after $50 \mathrm{yr}$ for Case (2), including heat effects from tank but no vapor diffusion.

\section{Discussion and Conclusions}

A dominant feature of vadose zone hydrologic behavior at the tank farms is the umbrella effect of the tanks, which diverts downward seepage laterally, giving rise to locally increased water fluxes outside the footprint of the tanks. Tank heat causes substantial redistribution of moisture and transient increases in water fluxes. The heat promotes partial formation drying, especially in the infiltration shadow beneath the tanks, but it does not prevent the tops and perimeters of tanks from being contacted by mobile liquid water.

Our simulations show some acceleration of downward water travel from the umbrella and thermal effects of the tank, but it should be noted that these predictions probably underestimate actual seepage velocities, perhaps by large amounts. In our "single region" heterogeneous porous medium model, pore velocity of water (= velocity of non-reactive solute) is calculated as

$$
\mathrm{v}=\frac{\mathrm{u}}{\phi \mathrm{S}_{1}}
$$




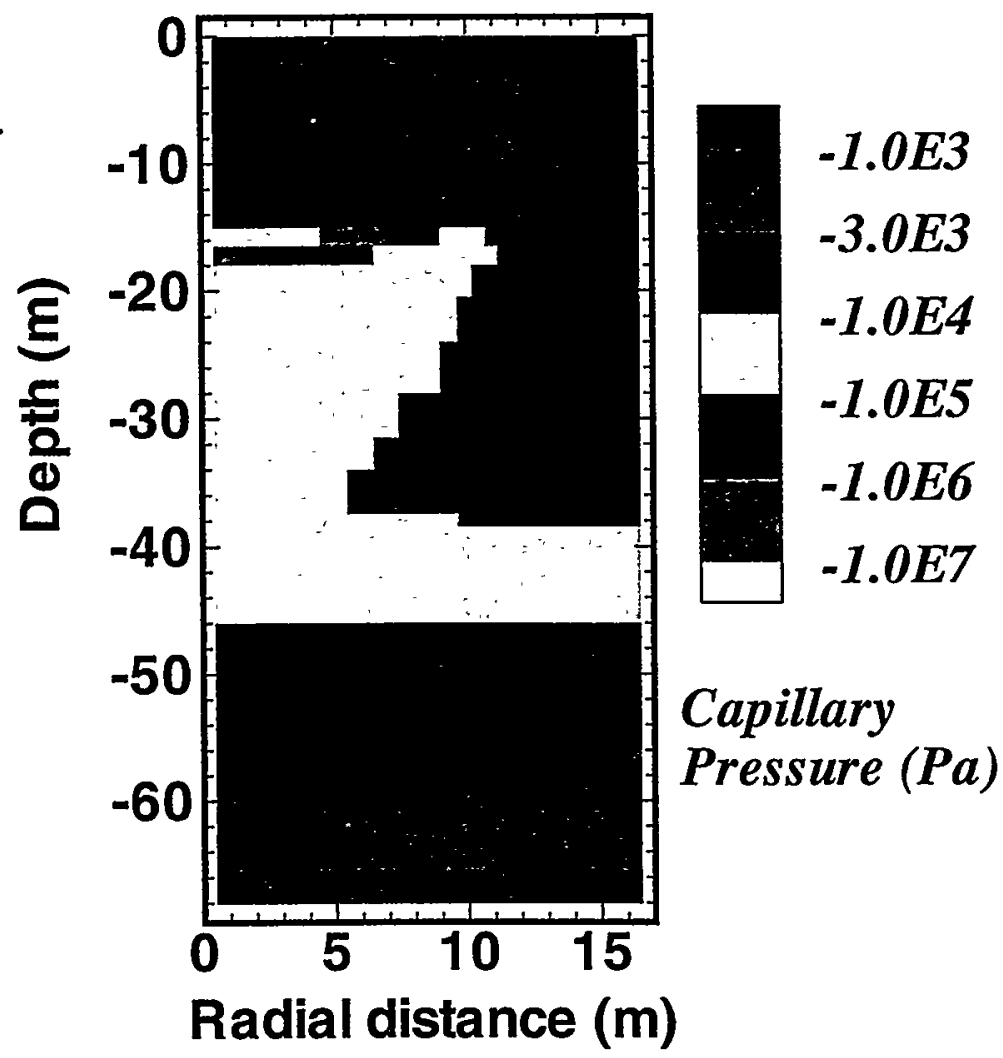

Figure 11. Suction pressures after 50 yr for Case (3), including heat effects from tank as well as vapor diffusion.

where $u$ is the Darcy velocity (volumetric flux, units of $\mathrm{m}^{3} / \mathrm{m}^{2} \mathrm{~s} \equiv \mathrm{m} / \mathrm{s}$ ). Eq. (7) assumes complete and instantaneous mixing of water throughout the pore space on the scale of space discretization (grid resolution). In reality we expect a distribution of pore velocities to be present, with water flowing slowly in some regions, more rapidly in others, with diffusive and dispersive exchange between regions flowing at different velocities, as well as with regions of stagnant water. Such "multi-region" behavior is especially likely for poorly sorted sediments, as at Hanford, where a broad range of grain and pore sizes is present. If a fraction of total flux $u$ ' $<u$ proceeds in a portion $\Delta \mathrm{S}^{\circ}<\mathrm{S}_{\mathrm{l}}$ of the water saturated pore space, pore velocity for this water would be

$$
\mathrm{v}^{\prime}=\frac{\mathrm{u}^{\prime}}{\phi \Delta \mathrm{S}_{\mathrm{I}}}
$$

which for $\Delta S \ll S_{1}$ could be considerably larger than average pore velocity v. Such effects can be modeled by means of multiple continua and multi-region approaches (Pruess and Narasimhan, 1985; Gwo et al., 1996). 
To illustrate a possible mechanism for accelerated solute transport, let us consider a multiregion model with "side-by-side" flow. More specifically, let us assume that, when the tank is emplaced and net infiltration is switched from 10 to $50 \mathrm{~mm} / \mathrm{yr}$, the increased water flux will entirely flow through that portion of the pore space that becomes water filled in addition to the pore space that was saturated at $10 \mathrm{~mm} / \mathrm{yr}$. Near the top of the Hanford unit just outside the perimeter of the tank, $\mathrm{S}_{1}$ changes from $39.49 \%$ to $52.71 \%$ in our isothermal simulation, for an increase of $\Delta \mathrm{S}_{1}$ $=13.22 \%$. From our simulation results and using Eq. (7), average pore velocity of downward water flow increases from $59.25 \mathrm{~mm} / \mathrm{yr}$ for the case of $10 \mathrm{~mm} / \mathrm{yr}$ infiltration, no tank, to 3.634 $\mathrm{m} / \mathrm{yr}$ for an isothermal simulation with tank and $50 \mathrm{~mm} / \mathrm{yr}$ infiltration. This substantial increase from the ambient value is due both to enhanced infiltration and the umbrella effect of the tank. From Eq. (8) pore velocity would be estimated at $13.77 \mathrm{~m} / \mathrm{yr}$, which represents a further increase by a factor of approximately 3.8 times in comparison to the estimate from Eq. (7).

Additional local flux enhancement with increased velocities of solute migration can arise from larger-scale heterogeneity of the geologic media, that could funnel a portion of distributed seepage into localized preferential flow paths (Kung, 1990a, b). Water flow and solute travel will be further complicated by the effects of dissolved solids in fluids leaked from tanks, which could alter the density, viscosity, surface tension, and contact angle of the aqueous phase. These effects as well as possible changes in formation porosity and permeability from chemical interactions could promote localized preferential flow; modeling studies to explore these phenomena are ongoing.

The ultimate objective of simulation studies at the Hanford tanks is development of detailed quantitative models that include all relevant physical and chemical processes, are calibrated to field observations, and can serve to explore the behavior of contaminants subject to different future scenarios. Such detailed mechanistic process models are needed to provide a sound basis for sitewide performance assessment and environmental management. The modeling studies presented here are preliminary and have a much more modest objective. By simulating the behavior of simplified systems we attempt to improve the understanding of coupled fluid flow and heat transfer processes at the tanks. It is hoped that this will aid in targeting future field, laboratory, and modeling studies for a more reliable assessment. We envision a need for ongoing iterative refinement of process models and parameters. Future work should aim at a more comprehensive description of processes, including tank leaks and the thermophysical and chemical behavior of leaked fluids, and should also improve the representation of hydrogeologic conditions and parameters with appropriate spatial and temporal resolution. Regardless of past and future 
characterization efforts, it is clear that many parameters will never be known with the accuracy, spatial coverage, and resolution that would be required for reliable deterministic modeling. Sensitivity studies and probability analyses will have to be important components of any modeling effort.

\section{Acknowledgement}

The author appreciates many stimulating discussions with colleagues from the Hanford S\&T modeling group, including Steve Yabusaki (PNNL), Peter Lichtner (LANL), and Carl Steefel (LLNL). Thanks are due to Paul Witherspoon, George Moridis and Tianfu Xu for a careful review of the manuscript and the suggestion of improvements. This work was supported by the U.S. Department of Energy under Contract No. DE-AC03-76SF00098 through Memorandum Purchase Order 248861-A-B2 between Pacific Northwest National Laboratory and Lawrence Berkeley National Laboratory.

\section{References}

Cass, A., G.S. Campbell and T.L. Jones. Enhancement of Thermal Water Vapor Diffusion in Soil. Soil Sci. Soc. Am. J., Vol. 48, no. 1, pp. 25 - 32, 1984.

Conaway, J.G., R.J. Luxmoore, J.M. Matuszek and R.O. Patt. TWRS Vadose Zone Contamination Issue Expert Panel Status Report, DOE/RL-RL-49, Rev. 0, Richland, WA, 1997.

Corey, A.T. The Interrelation Between Gas and Oil Relative Permeabilities, Producers Monthly, pp. 38 - 41, November 1954.

Edlefsen, N.E. and A.B.C. Anderson. Thermodynamics of Soil Moisture, Hilgardia, 15 (2), 31$298,1943$.

Gee, G.W., M.J. Fayer, M.L. Rockhold and M.D. Campbell. Variations in Recharge at the Hanford Site, Northwest Sci., Vol. 60, No. 4, pp. 237 - 250, 1992.

Gee, G.W. Vadose Zone Transport Field Study Project Broad Test Plan Rev. 1.0, presented at Advanced Vadose Zone Characterization Workshop, Richland, WA, January 19 - 20, 2000.

Gwo, J.P., P.M. Jardine, G.V. Wilson and G.T. Yeh. Using a Multiregion Model to Study the Effects of Advective and Diffusive Mass Transfer on Local Physical Nonequilibrium and Solute Mobility in a Structured Soil, Water Resour. Res., Vol. 32, No. 3, pp. 561 - 570, 1996.

Hirschfelder, J.O., C.F. Curtiss and R.B. Bird. Molecular Theory of Gases and Liquids, John Wiley \& Sons, New York, NY, 1954.

International Formulation Committee. A Formulation of the Thermodynamic Properties of Ordinary Water Substance, IFC Secretariat, Düsseldorf, Germany, 1967. 
Kung, K.J.S. Preferential Flow in a Sandy Vadose Zone: 1. Field Observation, Geoderma, Vol. 46, pp. 51-58, 1990.

Kung, K.J.S. Preferential Flow in a Sandy Vadose Zone: 2. Mechanism and Implications, Geoderma, Vol. 46, pp. 59-71, 1990.

Loomis, A.G. Solubilities of Gases in Water, in: International Critical Tables, Vol. III, E. W. Washburn, (ed.), McGraw-Hill, New York, NY, pp. 255-257, 1928.

Mualem, Y.A New Model for Predicting the Hydraulic Conductivity of Unsaturated Porous Media, Water Resour. Res., Vol. 12, No. 3, pp. 513 - 522, 1976.

Piepho, M.G. SX Tank Farm Vadose Zone Temperature Sensitivity Study, Report HNF-4744, Rev. 0, Fluor-Daniel Northwest, Inc., Richland, WA, 1999.

Philip, J.R. and D.A. de Vries. Moisture Movement in Porous Materials Under Temperature Gradients, EOS Trans. AGU, Vol. 38, No. 2, pp. 222 - 232, 1957.

Pruess, K. On Vaporizing Water Flow in Hot Sub-Vertical Rock Fractures, Transport in Porous Media, Vol. 28, pp. 335 - 372, 1997.

Pruess, K. and T.N. Narasimhan. A Practical Method for Modeling Fluid and Heat Flow in Fractured Porous Media, Soc. Pet. Eng. J., 25 (1), 14-26, February 1985.

Pruess, K., C. Oldenburg and G. Moridis. TOUGH2 User's Guide, Version 2.0, Lawrence Berkeley National Laboratory Report LBNL-43134, Berkeley, CA, November 1999.

Somerton, W.H., J.A. Keese and S.L. Chu. Thermal Behavior of Unconsolidated Oil Sands, paper SPE-4506, presented at 48th Annual Fall Meeting of the Society of Petroleum Engineers, Las Vegas, NV, 1973.

van Genuchten, M.Th. A Closed-Form Equation for Predicting the Hydraulic Conductivity of Unsaturated Soils, Soil Sci. Soc. Am. J., Vol. 44, pp. 892 - 898, 1980.

Vargaftik, N.B. Tables on the Thermophysical Properties of Liquids and Gases, 2nd Ed., John Wiley \& Sons, New York, NY, 1975.

Ward, A.L., G.W. Gee and M.D. White. A Preliminary Numerical Analysis of Contaminant Transport through the Vadose Zone of 241-SX Tank Farm, Pacific Northwest National Laboratory, Unpublished Report, Richland, WA, 1996.

Ward, A.L., G.W. Gee and M.D. White. A Comprehensive Analysis of Contaminant Transport in the Vadose Zone Beneath Tank SX-109, Pacific Northwest National Laboratory Report PNNL-11463, Richland, WA, 1997.

Webb, S.W. and C.K. Ho. Enhanced Vapor Diffusion in Porous Media - LDRD Final Report, Sandia National Laboratories Report SAND98-2772, Albuquerque, NM, 1998. 